\title{
Comparing the HbA1c Assay Results of Architect C 8000 and MQ-2000PT
}

\author{
Buket Kın Tekçe1, Hikmet Tekçe², Gülali Aktaş33, Mehmet Tosun ${ }^{1}$ \\ ${ }^{1}$ Department of Medical Biochemistry, Abant İzzet Baysal University Faculty of Medicine, Bolu, Turkey \\ ${ }^{2}$ Department of Internal Diseases, Division of Nephrology, Abant İzzet Baysal University Faculty of Medicine, Bolu, Turkey \\ ${ }^{3}$ Department of Internal Diseases, Abant İzzet Baysal University Faculty of Medicine, Bolu, Turkey
}

\begin{abstract}
Objective: Changes in a device and the modification of measurement methods are frequent issues in medical laboratories. The effects of such modifications on assay results should be investigated. $\mathrm{HbA} 1 \mathrm{c}$ is a widely used analyte in treatment and in the follow-up of diabetic patients. We aimed to evaluate the effects of two different assay methods on the detection of the percentage of $\mathrm{HbA} 1 \mathrm{c}$.

Methods: We used blood samples with K3-EDTA of 57 diabetic patients who were admitted to our laboratories for the HbA1c assay. HbA1c assays were performed using immunoturbidimetric (Architect C 8000; Abbot Laboratories Inc., Middletown, USA) and ion exchange chromatography (MQ2000PT; Shanghai Hui Zhong Medical Technology Co. Ltd., Shangai, China) methods. HbA1c assays were repeated two times in both devices. Results were analyzed using MedCalc software.

Results: Mean HbA1c level in immunoturbidimetric and ion exchange chromatography assays were 6.6 (min:4.1 and max:11.4) and 6.9 (min:4.9 and max:11.8), respectively. In the linear regression analysis, we detected an $r$ value of $0.9533(r<0.975)$. In Passing-Bablock analysis, we found the following equation, $\mathrm{y}=0.4+1.0 \times$ (intercept $\mathrm{Cl}$ : $-0.22-0.68$; slope $\mathrm{Cl}: 0.97-1.09$ ). We did not observe any constant or proportional systematic errors between the assay methods. We found a 0.37 difference between the two methods in the Bland-Altman graphs of mean HbA1c measurements (Bias $5.7 \%$ ).

Conclusion: Researches on the harmonization of $\mathrm{HbA} 1 \mathrm{c}$ are still increasing worldwide. However, at present, there are variations in methods and devices. NGSP suggests that the difference between methods should not exceed $\mathrm{HbA} 1 \mathrm{c} \pm 0.70$. We found that mean $\mathrm{HbA} 1 \mathrm{c}$ results were higher by 0.37 times in ion exchange chromatography assay compared with those in immunoturbidimetric assay. This difference is within the range suggested by NGSP. (JAREM 2015; 5: 52-5)
\end{abstract}

Keywords: HbA1c, standardization, method comparison

\section{INTRODUCTION}

Hemoglobin is a protein located in red blood cells and is responsible for oxygen transportation. Because of post-translational modifications after the synthesis of hemoglobin, modified hemoglobins are formed, and the most common among them is hemoglobin $\mathrm{A} 1 \mathrm{c}(\mathrm{HbA} \mathrm{C} c)$ (1). It has been known for a long time that the $\mathrm{HbA} 1 \mathrm{c}$ level reflects the average blood glucose level 6-8 weeks prior to measurement and that it correlates with the late complications of diabetes (2). In 1988, the American Diabetes Association (ADA) recommended the use of $\mathrm{HbA1} \mathrm{c}$ in the follow-up of diabetes (3). The estimated treatment goals for $\mathrm{HbA} 1 \mathrm{c}$ were determined by the ADA for the first time in 1994 (4). Today, while HbA1c maintains its importance in the follow-up of diabetes, it has also been used as a criterion for the diagnosis of diabetes (5).

$\mathrm{HbA1c}$ is a useful parameter because it has low biological variation, does not require any special preparation before the test, is not affected by acute stress, and has high preanalytical stability for diagnosis and follow-up treatment of diabetes (6). For HbA1c analysis, more than 70 methods are reported to be used worldwide (7). As each of these methods measures different fractions of glycated hemoglobin in different ways, the results may differ from each other (8). To ensure standardization for $\mathrm{HbA} 1 \mathrm{c}$ measurement methods, the National Glycohemoglobin Standardiza- tion Program (NGSP) was established in 1993 by the American Association for Clinical Chemistry (9). In 1995, the International Federation of Clinical Chemistry and Laboratory Medicine (IFCC) started standardization studies for HbA1c. In 2001, the reference method that had been established for $\mathrm{HbA} 1 \mathrm{c}$ was approved by the IFCC and was started to be used (10). Although the IFCC and NGSP have tried to resolve differences between methods through studies, a standardization that covers all methods that have been used worldwide has not yet been provided (8).

Changes in the device and the modification of measurement methods are frequent issues in medical laboratories. Studies have shown that there is a significant amount of bias between $\mathrm{HbA1c}$ levels detected by different methods (11). The effects of such modifications on assay results should be investigated, and clinicians should be informed about these possible changes. We aimed to evaluate the effects of two different $\mathrm{HbA} 1 \mathrm{c}$ assays on patient samples.

\section{METHODS}

\section{Collecting Blood Samples}

For this study, we used the samples of 57 patients who were admitted to the laboratories of Abant Izzet Baysal University Faculty of Medicine Research and Application Hospital for the HbA1c assay. The patients' venous blood samples were taken into tubes that were anticoagulated with K3-EDTA. All samples were incu- 
bated at room temperature, until they had been worked on, and the analysis was completed within $4 \mathrm{~h}$ at most.

\section{HbA1c Measurement Methods}

$\mathrm{HbA1c}$ was measured in accordance with the manufacturer's instructions in both methods. The patients' samples were examined twice in both systems.

1. Immunoturbidimetric method: In this method, the $\mathrm{HbA} 1 \mathrm{c}$ assay was conducted via an autoanalyzer (Architect C 8000, Abbott Laboratories, Inc., Middletown, USA). Before the measurement, samples were subjected to pretreatment with a denaturant (MULTIGENT hemoglobin denaturant). In this way, the decomposition of erythrocytes was achieved by exposing the erythrocytes to osmotic pressure. Afterwards, from the hemolysate that was obtained, two measurements were conducted with the autoanalyzer, including total hemoglobin and $\mathrm{HbA1c}$. The hemoglobin level was measured with the method described by Zander et al. (12). $\mathrm{HbA} 1 \mathrm{c}$ microparticle agglutination was immunoturbidimetrically measured with the inhibition method. Calibrator values that were used could be monitored by the IFCC and NGSP. The obtained results were converted to an $\mathrm{HbA1c}$ result with the below formula. With the help of this formula, $\mathrm{HbA} 1 \mathrm{c}$ results are reported to be correlated to the NGSP-certified method.

$$
[\mathrm{HbA} 1 \mathrm{c}(\mathrm{g} / \mathrm{dL}) \times 100]-3+[0.2 \times \mathrm{THb}(\mathrm{g} / \mathrm{dL})]=\% \mathrm{HbA} 1 \mathrm{c}
$$

$\mathrm{THb}(\mathrm{g} / \mathrm{dL})$

2. Ion-exchange chromatography: With this method, $\mathrm{HbA} 1 \mathrm{c}$ measurement was conducted with an automatic $\mathrm{HbA} 1 \mathrm{c}$ analysis device (MQ-2000PT, Shanghai Hua Zhong Medical Technology Co., Ltd., Shanghai, China) were performed. This device is based on HPLC and uses ion-exchange chromatography. Patient is ionically interacts with $\mathrm{HbA} 1 \mathrm{c}$ colon material that was in the sample and is separated from other hemoglobin fractions. Meanwhile, changes in absorbance are measured at $415 \mathrm{~nm}$. HbA1c that was measured was expressed as percentage. This method could be monitored by the reference method used by the IFCC.

\section{Statistical Analysis}

Statistical analysis was performed using the demo version of the MedCalc statistical software program. The compliance in the normal distribution of variables was examined with the KolmogorovSmirnov test. Values are expressed as average and standard deviation. Differences between averages were assessed by Student's t-test. $\mathrm{P}<0.05$ was considered to be significant. Regression analysis was performed to assess the relationship between results obtained from both methods. The results obtained by ion-exchange chromatography were defined as dependent variables. Because linear regression analysis results in the $r$-value of $<0.975$, PassingBablock regression analysis was performed. Bland-Altman plots were applied in order for method comparison.

\section{RESULTS}

The samples that were examined twice with the immunoturbidimetric method and ion-exchange chromatography were averaged for each method. These results were used for statistical analysis. The results that had been obtained fit in the normal distribution. The average results of $\mathrm{HbA} 1 \mathrm{c}$ level in the immunoturbidimetric and ion-exchange chromatography methods were $6.6 \%$
( $\min 4.1 \%$ and $\max 11.4 \%$ ) and $6.9 \%$ ( $\min 4.9 \%$ and $\max 11.8 \%$ ), respectively. There was no significant difference between the averages of both methods $(p=0.27)$. In linear regression analysis, the r-value was 0.9533. In the Passing-Bablock analysis, we found the following equation, $\mathrm{y}=0.4+1.0 x$ (intercept $\mathrm{Cl}$ : $-0.22-0.68$; slope Cl: 0.97-1.09) (Figure 1). No constant or proportional systematic errors were observed between the assay methods. Deviation from linearity was not observed between the methods ( $p>0.1)$. When the two methods were compared in Bland-Altman graphs, $\mathrm{HbA} 1 \mathrm{c}$ results obtained by ion-exchange chromatography were found to be higher by an average of 0.37 times than those obtained by the immunoturbidimetric method; this corresponded to $5.7 \%$ bias (Figure 2).

\section{DISCUSSION}

In this study where the effects of two different measurement methods for $\mathrm{HbA} 1 \mathrm{c}$ on patient samples were evaluated, it was reported that between the averages of results obtained by both methods, there was no statistically significant difference. Furthermore, it was determined that there was a linear relationship between the methods and that there was no constant or proportional error. Despite all this, it was suggested that the results obtained by ion-exchange chromatography were found to be higher by an average of 0.37 times and that this corresponded to $5.7 \%$ bias.

Today, $\mathrm{HbA} 1 \mathrm{c}$ is used in diabetes screening in addition to the diagnosis and treatment of diabetes. Therefore, it must be measured with a high accuracy and reliability (13). Furthermore, for the results that will be obtained in the same laboratory, the provision of its own standardization is particularly important. The method comparison we performed reveals the impact of method change on patient outcomes. In this study, HbA1c levels obtained by ion-exchange chromatography were found to be higher by an average of 0.37 times (5.7\%) than those obtained by the immunoturbidimetric method. The NGSP suggests that the difference between the methods should be in the range of $\mathrm{HbA} 1 \mathrm{c} \pm 0.70$ (8). The difference we found is within the limits suggested by the NGSP.

Physicians want the $\mathrm{HbA} 1 \mathrm{c}$ analysis of diabetic patients on a regular basis, and they assess results under the guidance of current guidelines on fixed threshold values (8). Possible differences between successive results are interpreted as the effects of diabetic regulation. According to the common idea, 0.5 of change in $\mathrm{HbA} 1 \mathrm{c}$ in the patient's results is interpreted as a clinically significant change (14). However, there are several factors resulting from biological and analytical variations that could lead to differences in results between the two measurements. If two consecutive measurements that are compared with each other are measured with two different methods, there is no doubt that one of the reasons for the difference observed between the results is the difference between methods (15). The $0.37 \mathrm{HbA} 1 \mathrm{c}$ difference we obtained between the two measurement methods in our patient group remains essentially below $0.5 \mathrm{HbA} 1 \mathrm{c}$ change level, which is considered to be clinically significant. However, it should be noted that when effects that may arise from biological and analytical variations are added, the changes between successive results may exceed the $0.5 \mathrm{HbA} 1 \mathrm{c}$ limit. The effect of the biological variation for $\mathrm{HbA} 1 \mathrm{c}$ is given as $<2 \%$ (14). 


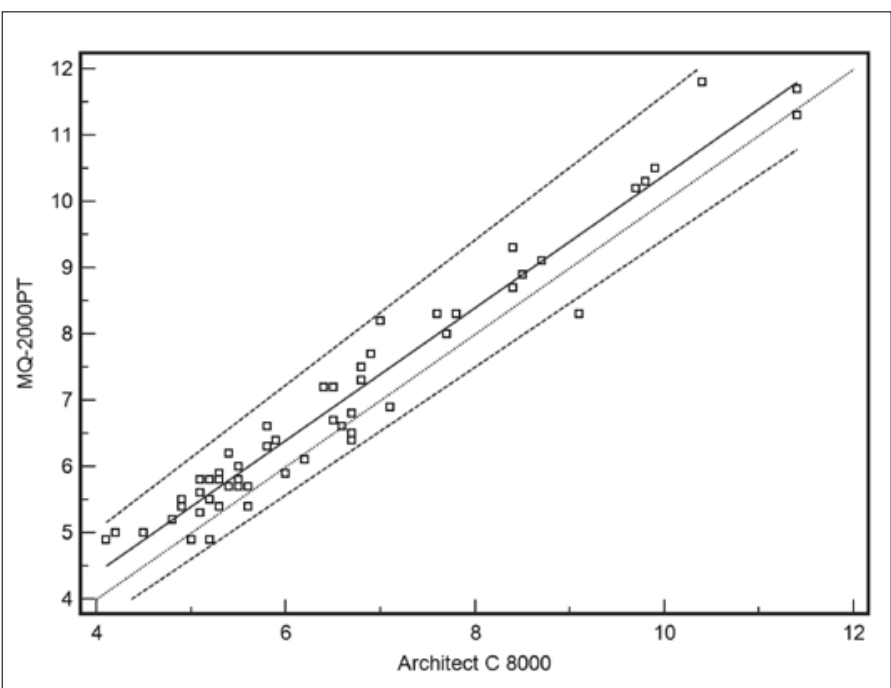

Figure 1. Passing-Bablock regression graph. In Passing-Bablock analysis, the following equation was obtained: $y=0.4+1.0 \times$ (intercept $\mathrm{Cl}$ : $-0.22-0.68$; slope $\mathrm{Cl}$ : 0.97-1.09).

Therefore, it has little effect on patient outcomes. Although the impact of analytical variation varies from method to method, the coefficients of variation of the two measurement methods that we compared were also reported to be lesser than $2 \%$. Under these circumstances, in consecutive results, biological and analytical variations appear to be a factor that will adversely affect the evaluation of the results alone. However, it should be remembered that when the impact of differences in methods is also included, clinical decision making might be adversely affected. Therefore, when assessing the results after the change of method, the total impact of all these factors on patient outcomes must be taken into account, and the results should be accordingly interpreted.

The methods used for $\mathrm{HbA} 1 \mathrm{c}$ measurement have two basic principles (16). The first one includes methods such as chromatography or electrophoresis that separate $\mathrm{HbA} 1 \mathrm{c}$ from other hemoglobin fractions. The other approach is immunochemical methods, in which antigens targeting $\mathrm{HbA} 1 \mathrm{c}$ are used. Results obtained with these methods are not correlated to each other, and there are some differences between methods and devices. To eliminate the probable negative impacts of these differences on patient outcomes, studies are underway worldwide on $\mathrm{HbA} 1 \mathrm{c}$ harmonization. However, there is no standardization that covers all methods and devices (17). The calibrators that were used in both methods we compared can be monitored by the IFCC and NGSP. Although the results were compatible with each other, there is still a difference to be considered between the two methods. This difference highlights that it is necessary to assess the impact of this difference on the results when there is a change of device in laboratories, although the methods can be monitored with a standardized method.

The strength of this study is using the Bland-Altman analysis that is considered to be the golden standard in the statistical analysis of method comparison studies. According to this statistical analysis method, the measurement differences of both methods are presented, and interpreting the admissibility level of these differences is left to the clinician's judgement.

The weakness of this study is its single-center design and the lim-

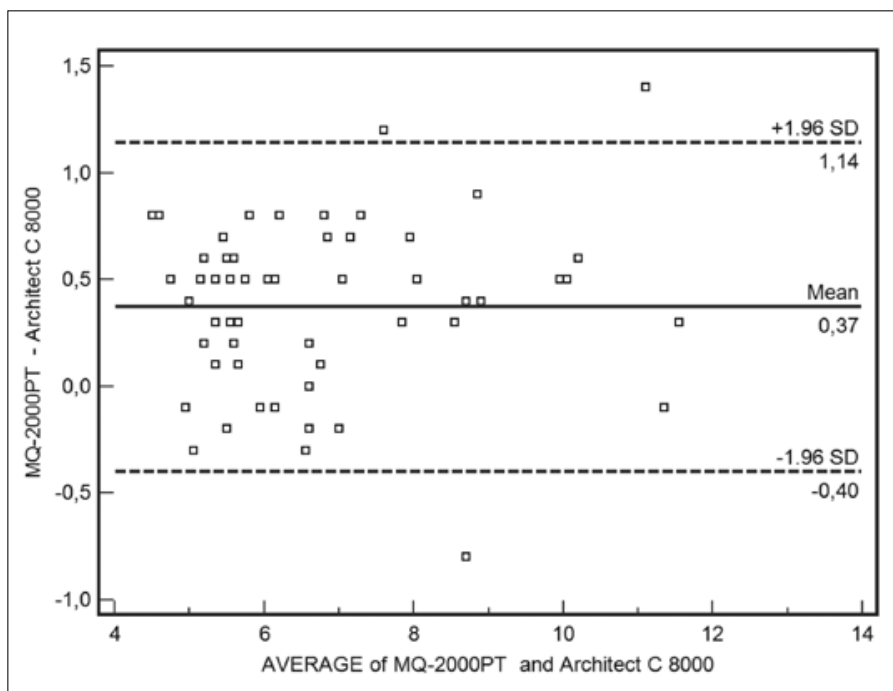

Figure 2. Bland-Altman graph. HbA1c results obtained by ionexchange chromatography were found to be higher by an average of 0.37 times than those obtained by the immunoturbidimetric method.

ited patient population. Furthermore, no recurrence study was performed for methods that were used.

\section{CONCLUSION}

The results of this study show that $\mathrm{HbA1}$ c results obtained by the MQ-2000PT device were 0.37-times higher in the ion-exchange chromatography assay than those in the immunoturbidimetric assay that used ARCHITECT C 8000 . This difference is within the range suggested by the NGSP. Nevertheless, we believe that informing clinicians about these differences would be useful for the follow-up and treatment of diabetic patients.

Ethics Committee Approval: The study is outside of the regulations about clinical trials.

Informed Consent: The study is outside of the regulations about clinical trials.

Peer-review: Externally peer-reviewed.

Author Contributions: Concept - B.K.T., H.T., G.A., M.T.; Design - B.K.T., H.T., G.A., M.T.; Supervision - B.K.T., H.T., G.A., M.T.; Resource - B.K.T.; Materials - B.K.T.; Data Collection and/or Processing - B.K.T., H.T., G.A., M.T.; Analysis and/or Interpretation - B.K.T., H.T.; Literature Review B.K.T., H.T.; Writer - B.K.T., H.T.; Critical Review- B.K.T., H.T., G.A.

Acknowledgements: The authors would like to thank the laboratory staff.

Conflict of Interest: No conflict of interest was declared by the authors.

Financial Disclosure: The authors declared that this study has received no financial support.

\section{REFERENCES}

1. Radin MS. Pitfalls in Hemoglobin A1c Measurement: When Results may be Misleading. J Gen Intern Med 2014; 29: 388-94. [CrossRef]

2. Kaiser $P$, Reinauer $\mathrm{H}$. Diabetes mellitus: the long way of standardization of $\mathrm{HbA}(1 \mathrm{c})$ to the level of highest metrological order. Ger Med Sci 2011; 9: Doc28.

3. Sacks DB. Measurement of hemoglobin A(1c): a new twist on the path to harmony. Diabetes Care 2012; 35: 2674-80. [CrossRef]

4. Little RR, Rohlfing CL, Sacks DB; National Glycohemoglobin Standardization Program (NGSP) Steering Committee. Status of hemog- 
lobin A1c measurement and goals for improvement: from chaos to order for improving diabetes care. Clin Chem 2011; 57: 205-14. [CrossRef]

5. American Diabetes Association. Diagnosis and classification of diabetes mellitus. Diabetes Care 2010; 33: S62-9. [CrossRef]

6. Day A. HbA1c and diagnosis of diabetes. The test has finally come of age. Ann Clin Biochem 2012; 49: 7-8. [CrossRef]

7. Goodall I, Colman PG, Schneider HG, McLean M, Barker G. Desirable performance standards for $\mathrm{HbA}(1 \mathrm{c})$ analysis - precision, accuracy and standardisation: consensus statement of the Australasian Association of Clinical Biochemists (AACB), the Australian Diabetes Society (ADS), the Royal College of Pathologists of Australasia (RCPA), Endocrine Society of Australia (ESA), and the Australian Diabetes Educators Association (ADEA). Clin Chem Lab Med 2007; 45: 1083-97. [CrossRef]

8. Little RR, Rohlfing CL, Sacks DB; National Glycohemoglobin Standardization Program (NGSP) Steering Committee. Status of hemoglobin A1c measurement and goals for improvement: from chaos to order for improving diabetes care. Clin Chem 2011; 57: 205-14. [CrossRef]

9. Little RR, Rohlfing $\mathrm{CL}$, Wiedmeyer HM, Myers GL, Sacks DB, Goldstein DE; NGSP Steering Committee. The national glycohemoglobin standardization program: A five-year progress report. Clin Chem 2001; 47: 1985-92.

10. Jeppsson JO, Kobold U, Barr J, Finke A, Hoelzel W, Hoshino T, et al. Approved IFCC reference method for the measurement of $\mathrm{HbA}(1 \mathrm{c})$ in human blood. Clin Chem Lab Med 2002; 40: 78-89. [CrossRef]
11. Genc S, Omer B, Aycan-Ustyol E, Ince N, Bal F, Gurdol F. Evaluation of turbidimetric inhibition immunoassay (TINIA) and HPLC methods for glycated haemoglobin determination. J Clin Lab Anal 2012; 26: 481-5. [CrossRef]

12. Zander R, Lang W, Wolf HU. Alkaline haematin D-575, a new tool for the determination of haemoglobin as an alternative to the cyanhaemiglobin method. I. Description of the method. Clin Chim Acta 1984; 136: 83-93 [CrossRef].

13. Juarez DT, Demaris KM, Goo R, Mnatzaganian $C L$, Wong Smith $H$. Significance of $\mathrm{HbA} 1 \mathrm{c}$ and its measurement in the diagnosis of diabetes mellitus: US experience. Diabetes Metab Syndr Obes 2014; 7 487-94. [CrossRef]

14. Nathan DM, Buse JB, Davidson MB, Ferrannini E, Holman RR, Sherwin $R$, et al. Medical management of hyperglycemia in type 2 diabetes: a consensus algorithm for the initiation and adjustment of therapy a consensus statement of the American Diabetes Association and the European Association for the Study of Diabetes. Diabetes Care 2009; 32: 193-203. [CrossRef]

15. Holmes EW, Erşahin C, Augustine GJ, Charnogursky GA, Gryzbac $\mathrm{M}$, Murrell JV, et al. Analytic bias among certified methods for the measurement of hemoglobin A1c: a cause for concern? Am J Clin Pathol 2008; 129: 540-7. [CrossRef]

16. Homa K, Majkowska L. Difficulties in interpreting $\mathrm{HbA}(1 \mathrm{c})$ results. Pol Arch Med Wewn 2010; 120: 148-54.

17. International Expert Committee. International Expert Committee report on the role of the $\mathrm{A} 1 \mathrm{C}$ assay in the diagnosis of diabetes. Diabetes Care 2009; 32: 1327-34. [CrossRef] 